\title{
Cytogenetic Damage in Blood Lymphocytes and Exfoliated Epithelial Cells of Children With Inflammatory Bowel Disease
}

\author{
NINA HOLLAND, PAUL HARMATZ, DANIEL GOLDEN, ALAN HUBBARD, YEN-YING WU, JIN BAE, CONNIE CHEN, \\ KAREN HUEN, AND MELVIN B. HEYMAN
}

\begin{abstract}
School of Public Health [N.H., D.G., A.H., Y.-Y.W., J.B., C.C., K.H.], University of California, Berkeley, Berkeley, California 94720; Childrens Hospital \& Research Center [P.H.] Oakland, CA 94609; Department of Pediatrics [M.B.H.], University of California, San
\end{abstract} Francisco, San Francisco, California 94143

\begin{abstract}
This longitudinal, prospective study sought to establish whether pediatric Crohn's disease (CD) and ulcerative colitis (UC) are associated with increased levels of cytogenetic damage and whether folate supplementation in combination with other treatments mitigates cytogenetic damage in children with inflammatory bowel disease (IBD). After a 1-mo treatment and folate supplementation, all clinical tests in CD $(n=24)$ and UC $(n=17)$ patients improved. Patients with $\mathrm{CD}$ were comparable in the cytogenetic response with controls $(n=28)$ assessed by micronucleus (MN) assay, but both groups differed from the UC group. While the MN frequency in epithelial cells slightly decreased from first to second observations in CD patients $(p=0.05)$ and controls $(p=0.11)$, an increase was observed in UC patients $(p=0.001)$. Similar changes were observed in blood lymphocytes resulting in significantly higher levels of the MNs and chromosome bridges in UC patients. These preliminary findings of a difference in chromosome damage between pediatric UC patients compared with CD patients and healthy controls warrant confirmation and expansion to determine (1) the role of cytogenetic damage in the pathogenesis of these diseases, (2) relative contribution of treatment and folate supplementation, and (3) potential links to the eventual development of cancer in some patients. (Pediatr Res 61: 209-214, 2007)
\end{abstract}

$I^{\mathrm{B}}$ $\mathrm{BD}$ is characterized by chronic inflammation and ulceration of the gastrointestinal (GI) tract. The two primary forms of IBD, CD and UC, differ by disease mechanism, location, and character of the lesions in the GI tract and by endoscopic, radiographic, and histologic findings. UC predominantly involves the colon, whereas CD can affect any portion of the GI tract including the oral cavity (1). Despite these differences, patients with CD or UC manifest several similarities including inflammatory infiltrates in the GI tract, folate deficiency, and increased risk of cancer $(1,2)$.

The risk of colorectal cancer in patients with IBD is increased four- to 20 -fold compared with the general population, and some malignancies can develop in apparently uninvolved sites $(3,4)$. Patients with UC and CD have been reported to

Received April 24, 2006; accepted September 18, 2006.

Correspondence: Nina T. Holland, Ph.D., University of California-Berkeley, 759 University Hall, Berkeley, CA 94720-7360; e-mail: ninah@berkeley.edu

Supported by grants from the Packard Foundation, the Crohn's and Colitis Foundation of America, and NIH (M01 RR01271 and K24 DK60617). The contents of this article are solely the responsibility of the authors and do not necessarily represent official views of the Packard Foundation, the Crohn's and Colitis Foundation of America, and NIH.

DOI: $10.1203 /$ pdr.0b013e31802d77c7 develop leukemia, suggesting a potential relationship between IBD and leukemia (5). While the pathologic mechanism of IBD remains elusive, one typical characteristic of patients with IBD is folate deficiency $(4,6)$. Reduced red blood cell folate levels have been noted in patients with UC and colorectal cancer compared with a control group who did not have colorectal cancer (7). Moreover, one of the primary therapies for IBD is sulfasalazine (SASP), which also increases the risk of folate deficiency (8).

Folate supplementation is recommended for IBD patients taking SASP to compensate for potential folate deficiency, but adequate and consistent treatments have not been established. Hanauer et al. (9) has reported that folate levels can be normalized in about $80 \%$ of adult patients supplemented with folic acid. IBD frequently affects children (10-12). However, data pertaining to the effects of supplementation of pediatric patients are lacking. Additionally, data on the molecular or cytogenetic effects of IBD, folate deficiency, and treatment combined with folate supplementation in any IBD patients are sparse. One available report notes increased cytogenetic damage measured by chromosome aberrations in lymphocytes of adults with CD compared with controls (13). A possible explanation is that oxidative damage ensues, caused by altered characteristics of inflamed mucosa and generation of oxygenderived free radicals by phagocytic cells (14). The impact of folate deficiency, which could potentially increase both oxidative damage and uracil misincorporation, was not investigated. In a group of folate-deficient volunteers, misincorporation of uracil into DNA, and an increased frequency of micronucleated erythrocytes, presumably resulting from chromosome breaks, were observed (15).

The intestinal inflammatory response characteristic of IBD produces a cascade of events during which activated leukocytes infiltrate the intestinal wall and phagocytic cells are inappropriately activated. This triggers formation of reactive oxygen species (ROS), highly reactive byproducts of normal aerobic cellular function that can induce damage to macromolecules $(14,16)$. Environmental stressors and disease status can exacerbate free radical formation. The mucosa of IBD

Abbreviations: BNs, binucleated lymphocytes; CD, Crohn's disease; IBD, inflammatory bowel disease; GI, gastrointestinal; NBs, nucleoplasmic bridges; RI, replicative index; UC, ulcerative colitis 
patients is relatively depleted of antioxidant defenses, rendering them more susceptible to oxidative injury. A growing body of literature suggests that blocking these ROS should therefore alleviate inflammatory responses in the intestinal tracts (17). Recent studies have found that CD patients (18) and UC patients (19) who received supplemental antioxidants showed greatly reduced indices of oxidative stress.

Oxidative stress is potentially responsible for DNA damage, which can be measured by MN assay. MNs are formed by fragments of chromosomes or whole chromosomes lost from the main nucleus at the time of mitosis. MNs are widely used as biomarkers of cytogenetic damage for occupational and environmental exposures and diseases $(20,21)$, and recent studies have shown that MN frequency predicts an increased risk of cancer (22). In addition, MNs can be analyzed in a variety of human cells including blood lymphocytes and buccal and urothelial epithelia $(20,23)$. Previously, few studies, all in adults, have explored cytogenetic damage associated with IBD.

This study investigates the hypotheses that cytogenetic damage measured by $\mathrm{MN}$ assay is elevated in pediatric $\mathrm{CD}$ and UC patients compared with controls and that this damage can be mitigated by 1 mo of treatment combined with folate supplementation.

\section{MATERIALS AND METHODS}

Study design. This prospective, longitudinal study was conducted in clinics at the University of California, San Francisco (UCSF) Children's Hospital and the Children's Hospital \& Research Center Oakland (CHRCO). IBD and control groups took an oral folic acid supplementation over a 1-mo period. Cytogenetic analyses of MNs, nucleoplasmic bridges (NBs), and markers of cell death and proliferation were performed at the University of California, Berkeley (UCB).

Patients. A total of 69 subjects, whose ages ranged between 4 and 18 y old, were enrolled in this study. Inclusion criteria required that control subjects could not have preexisting acute or chronic illnesses and that all subjects were not taking daily folate/vitamin $\mathrm{B}_{12}$ multivitamin supplements at the time of enrollment. Recruited IBD patients were newly diagnosed with IBD as determined by endoscopic, radiographic, or histopathologic assays. The final patient population included $41 \mathrm{IBD}$ patients (24 CD and $17 \mathrm{UC}$ ) and 28 controls, which were frequency matched for age, gender, and ethnicity. A summary of enrollment statistics is given in Table 1.

Whites (self-identified) composed more than $50 \%$ of the patient population for both CD and UC groups, followed by African Americans and Asians. Despite the large age range (4-18 y old), average ages were similar in the control and IBD groups $(12.3 \pm 3.5$ versus $11.8 \pm 3.9 \mathrm{y}$, respectively). Overall, male IBD patients outnumbered female patients ( 21 and 15 , respectively) with $66 \%$ of males among CD patients, $46 \%$ among UC patients, and $54 \%$ in the control group.

Each patient took a 1-mg folic acid tablet daily for a 30-d supplementation period. Concurrently, IBD patients received standard treatment (Asacol/ Azulfidine, 6MP, and/or corticosteroids). Controls were given oral folate tablets $(1 \mathrm{mg})$. Patients of legal age or their parents/legal guardians provided written informed consent as approved by the Institutional Review Board of

Table 1. Patient enrollment summary

\begin{tabular}{|c|c|c|c|c|c|c|c|c|}
\hline \multirow[b]{2}{*}{ Group } & \multirow[b]{2}{*}{$n$} & \multirow[b]{2}{*}{$\%$ Males } & \multirow{2}{*}{$\begin{array}{c}\text { Age, y } \\
\text { (mean SD) }\end{array}$} & \multicolumn{5}{|c|}{ Ethnicity } \\
\hline & & & & W & AA & $\mathrm{H}$ & A & Other \\
\hline Control & 28 & 54 & $12.8 \pm 3.4$ & 23 & 1 & 1 & 1 & 2 \\
\hline $\mathrm{CD}$ & 24 & 65 & $12.7 \pm 3.8$ & 17 & 4 & 1 & 1 & 1 \\
\hline $\mathrm{UC}$ & 17 & 46 & $10.9 \pm 3.8$ & 10 & 3 & 1 & 1 & 2 \\
\hline
\end{tabular}

SD, standard deviation; W, white; H, Hispanic; AA, African American; A, Asian; O, other.
Children's Hospital Oakland, the Committee on Human Research of UCSF, and the Committee for the Protection of Human Subjects, UCB.

Cell collection, processing, and culture. Blood was collected in heparin vacutainers after an 8-h fasting period. Initial baseline measurements (collection 1) for buccal and urothelial exfoliated cells and blood were collected at the hospital of diagnosis (UCSF or CHRCO) from newly diagnosed patients and their matching controls. Collection 2 took place after 1 mo of folate supplementation (all subjects) and treatment (IBD patients).

Blood sample diagnostics. To determine disease activity before and after 1 mo of treatment and folic acid supplementation, UCSF or CHRCO clinical laboratories assessed complete blood counts for erythrocyte sedimentation rate (ESR), albumin concentration, and hematocrit, part of the Pediatric Crohn's Disease Activity Index that is used as a measure of disease severity (11). Folate levels were measured in red blood cells, and vitamin $B_{12}$ and homocysteine levels in plasma using standard laboratory assays (24).

Cytogenetic analysis. Methods of cell collection, processing, and scoring criteria for exfoliated cells and peripheral lymphocytes have been described previously (24). Briefly, Ficoll-isolated lymphocytes were cultured for $72 \mathrm{~h}$. Cytochalasin (Sigma Chemical Co., St. Louis, MO) was added to the cultures $44 \mathrm{~h}$ post-initiation to arrest cytokinesis. Cells were spun directly on the slides, fixed in methanol, and stained with Giemsa. At least two slides were scored for an average of 1000 binucleated lymphocytes (BNs) for each patient. Frequencies of MNs and NBs were used to assess cytogenetic damage. Percentage of apoptotic and necrotic cells was used as markers of cell death. Replicative index (RI) was calculated to measure cell proliferation in lymphocyte cultures as follows: $\mathrm{RI}=[(1 \times \%$ mononuclear cells $)+(2 \times$ $\%$ binuclear cells $)+(3 \times \%$ trinuclear cells $)+(4 \times \%$ tetranuclear cells)]/100.

Exfoliated cells were obtained by either gently swabbing oral mucosa on inner side of both cheeks with a cytobrush or spinning down urine to collect urothelial cells. In both cases, two washes with a buffer solution were performed followed by fixation in methanol and staining in Feulgen Fast-

Table 2. Clinical results

\begin{tabular}{|c|c|c|c|c|c|}
\hline Blood parameter & No. & Collection 1 & Collection 2 & $\Delta$ Mean & $p$ \\
\hline \multicolumn{6}{|l|}{ Control } \\
\hline Folate, ng/mL & 10 & $600 \pm 144$ & $754 \pm 87$ & $+154^{*}$ & 0.006 \\
\hline $\begin{array}{l}\text { Homocysteine, } \\
\mu \mathrm{mol} / \mathrm{L}\end{array}$ & 10 & $8.2 \pm 2.7$ & $6.4 \pm 0.7$ & $-1.8^{*}$ & 0.048 \\
\hline $\begin{array}{l}\text { Vitamin } \\
\mathrm{B}_{12}, \mathrm{pg} / \mathrm{mL}\end{array}$ & 10 & $824 \pm 448$ & $799 \pm 496$ & -25 & \\
\hline Albumin, $\mathrm{g} / \mathrm{dL}$ & 11 & $4.3 \pm 0.2$ & $4.2 \pm 0.2$ & -0.1 & 0.049 \\
\hline Hematocrit, \% & 10 & $40 \pm 3$ & $38 \pm 2$ & $-2 *$ & 0.006 \\
\hline $\mathrm{ESR}, \mathrm{mm} / \mathrm{h}$ & 10 & $5 \pm 4$ & $5 \pm 4$ & 0 & \\
\hline \multicolumn{6}{|l|}{ CD } \\
\hline Folate, ng/mL & 8 & $743 \pm 140$ & $854 \pm 218$ & +111 & \\
\hline $\begin{array}{l}\text { Homocysteine, } \\
\mu \mathrm{mol} / \mathrm{L}\end{array}$ & 7 & $8.3 \pm 2.5$ & $8.6 \pm 2.6$ & +0.3 & \\
\hline $\begin{array}{l}\text { Vitamin } \\
\quad \mathrm{B}_{12}, \mathrm{pg} / \mathrm{mL}\end{array}$ & 8 & $902 \pm 549$ & $704 \pm 403$ & -198 & \\
\hline Albumin, $\mathrm{g} / \mathrm{dL}$ & 17 & $3.1 \pm 0.8$ & $3.6 \pm 0.5$ & $+0.5^{*}$ & 0.006 \\
\hline Hematocrit, \% & 19 & $35 \pm 5$ & $36 \pm 7$ & +1 & \\
\hline $\mathrm{ESR}, \mathrm{mm} / \mathrm{h}$ & 18 & $29 \pm 21$ & $19 \pm 16$ & $-10^{*}$ & 0.005 \\
\hline \multicolumn{6}{|l|}{$\mathrm{UC}$} \\
\hline Folate, ng/mL & 7 & $767 \pm 214$ & $853 \pm 235$ & +86 & \\
\hline $\begin{array}{l}\text { Homocysteine, } \\
\mu \mathrm{mol} / \mathrm{L}\end{array}$ & 6 & $6.7 \pm 1.5$ & $7.7 \pm 3.6$ & +1 & \\
\hline $\begin{array}{l}\text { Vitamin } \\
\mathrm{B}_{12}, \mathrm{pg} / \mathrm{mL}\end{array}$ & 7 & $901 \pm 216$ & $810 \pm 162$ & -91 & \\
\hline Albumin, $\mathrm{g} / \mathrm{dL}$ & 12 & $3.6 \pm 0.6$ & $4.0 \pm 0.4$ & $+0.4^{*}$ & 0.024 \\
\hline Hematocrit, \% & 13 & $35 \pm 8$ & $38 \pm 3$ & +3 & \\
\hline $\mathrm{ESR}, \mathrm{mm} / \mathrm{h}$ & 11 & $23 \pm 19$ & $9 \pm 9$ & $-14 *$ & 0.031 \\
\hline
\end{tabular}

Results are presented as mean \pm SD. Patient blood profiles obtained from control, UC, and CD groups: typical blood parameter values for a healthy pediatric patient are as follows: albumin $\geq 3.5 \mathrm{~g} / \mathrm{dL}$, ESR $<20 \mathrm{~mm} / \mathrm{h}$, hematocrit $>33 \%$. Folate levels were measured in red blood cells.

Complete clinical results were not available for five controls and seven IBD patients, who were not included in this table.

* Statistical significance when $p<0.05 ; p$ values provided if this criterion was fulfilled. 

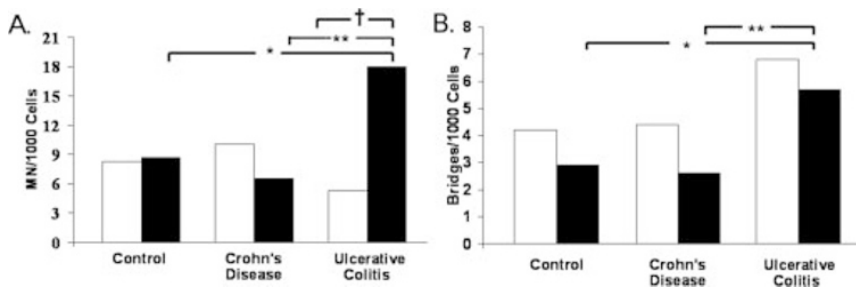

Figure 1. Cytogenetic damage in lymphocytes. (A) Frequency of MNs and frequency of $\mathrm{NBs}(B)$ in patients with IBD before (collection 1, open columns) and after (collection 2, solid columns) 1 mo of treatment and folate supplementation in IBD patients and folate supplementation in controls. Statistical analysis was conducted using GEE models and took advantage of longitudinal study design and by-pair comparisons of repeated samples from the same subjects. Statistically significant differences between groups and between collections are shown as follows: $* p<0.05$; $* * p<0.01$, and $\dagger p<0.001$.

Green. On average, 2000 cells were scored per subject, and MN frequencies were assessed separately in normal and degenerated epithelial cells as previously described in detail (25).

All scoring of randomly mixed and coded slides was conducted using the Nikon microscope under $1000 \times$ magnification. MN criteria for lymphocytes and epithelial cells were previously described $(25,26)$. At least $10 \%$ of slides were rescored for quality assurance, and variance did not exceed $25 \%$, which is consistent with criteria of HUMN (The International Collaborative Project on Micronucleus Frequency in Human Populations) (26).

Statistical analysis. All associations were examined using a generalized estimating equation (GEE) approach to account for the potential correlation of outcomes measured more than once on the same subject (27). For the noncount outcomes (RI and percentage of degenerated cells) GEE linear regression was used, whereas GEE Poisson regression was used for all other outcomes. This approach eliminated a significant part of the variability by excluding (1) interindividual variability and (2) intraindividual variability unrelated to treatment and folate supplementation and was more adequate for our longitudinal study design than traditional analysis of variance ANOVA. The GEE method is also advantageous in many instances because it does not depend on the type of data distribution. Age, gender, and ethnicity were also considered as possible covariates. Statistical significance was defined as $p<$ 0.05 .

\section{RESULTS}

Clinical results. Changes in average blood parameter values suggested an overall improvement in disease activity for IBD groups after the month-long folate supplementation period. Serum albumin significantly increased in the IBD groups after folate supplementation (UC: $3.6 \pm 0.6$ to $4.0 \pm 0.4 \mathrm{~g} / \mathrm{dL}$, $p=0.024$; CD: $3.1 \pm 0.8$ to $3.6 \pm 0.5 \mathrm{~g} / \mathrm{dL}, p=0.006$; Table 2). ESR decreased dramatically for both IBD categories, UC $(23 \pm 19$ to $9 \pm 9 \mathrm{~mm} / \mathrm{h}, p=0.03)$ and $\mathrm{CD}(29 \pm 21$ to $19 \pm 16 \mathrm{~mm} / \mathrm{h}, p=0.005)$. Hematocrit decreased slightly only in the control patients, from $40 \pm 3 \%$ to $38 \pm 2 \%$ ( $p=$ 0.006). Folate levels increased in all three groups after supplementation. However, this increase reached statistical sig- nificance only for the control group $(600.8 \mathrm{ng} / \mathrm{mL}$ to 754.9 $\mathrm{ng} / \mathrm{mL} ; p=0.006)$. A corresponding decrease in homocysteine levels, from 8.2 to $6.4 \mu \mathrm{mol} / \mathrm{L}(p<0.05)$ was seen in the control group, while levels in IBD patients did not change. Finally, all subgroups of patients experienced a nonsignificant decline in serum vitamin $\mathrm{B}_{12}$ levels (Table 2).

Cytogenetic damage in peripheral lymphocytes. At baseline (collection 1), cytogenetic damage (as measured by the frequency of MNs/1000 BNs) was slightly lower in UC patients than in controls $(p=0.07)$ and in CD patients $(p=$ 0.08 , Fig. 1A). However, after 1 mo of treatment and folate supplementation (collection 2), UC patients had significantly higher $\mathrm{MN}$ frequencies than controls $(p=0.03)$ and $\mathrm{CD}$ patients $(p=0.004$, Fig. $1 A)$. Although MN frequency appeared to decline in $\mathrm{CD}$ patients after supplementation and treatment from 10.1 to $6.5 \mathrm{MNs} / 1000$ cells, $p=0.12$, MN frequency remained similar at both collection times in controls (8.3 and 8.7 MNs/1000 cells, Table 3).

After treatment in combination with folate supplementation, we observed an overall trend of a lower frequency of the NBs, reflective of decreased chromosomal breakage (21), across all groups (Fig. 1B). Again, UC patients had significantly higher levels of damage during second collection than both controls $(p=0.02)$ and CD patients $(p=0.01)$. Overall, males in our study had significantly lower frequency of NBs than females $(p=0.02)$. NB frequency increased with age $(p=0.005)$ and differed by ethnicity with African Americans having the highest and Asians the lowest levels of MNs with Whites and Hispanics sharing similar intermediate values of MN frequency $(p<0.001)$.

In both groups of patients, the prevalence of apoptotic cells, a marker of programmed cell death, decreased after supplementation and treatment $(p=0.008$ and $p=0.002$, respectively; Fig. 2A). The control group had significantly fewer apoptotic cells than $\mathrm{CD}(p=0.03)$ and UC patients $(p=$ 0.002 ). As with the MN frequency, ethnicity was also associated with the frequency of apoptotic cells $(p=0.001)$, with Whites having more apoptotic cells than with non-Whites. The frequency of necrotic cells, another marker for cell death in human lymphocytes, declined in controls, possibly reflecting the positive effect of folate supplementation $(p=0.03)$. UC patients had significantly higher prevalence of necrotic cells than the control group subjects at the second collection ( $p=$ 0.04, Fig. 2B).

Lastly, cell proliferation in primary lymphocyte cultures, as measured by the RI, did not change following supplementa-

Table 3. MN assay in cultured blood lymphocytes

\begin{tabular}{|c|c|c|c|c|c|c|}
\hline Group & Collection & MNs/1000 cells & Bridges/1000 cells & $\%$ Apoptotic cells & $\%$ Necrotic cells & RI \\
\hline \multirow{2}{*}{ Control $(n=26)$} & 1 & $8.3 \pm 11.5$ & $4.2 \pm 3.9$ & $2.1 \pm 1.6$ & $15.1 \pm 14.6$ & $1.6 \pm 0.2$ \\
\hline & 2 & $8.7 \pm 10.7$ & $2.9 \pm 2.7$ & $1.8 \pm 1.3$ & $8.3 \pm 5.6$ & $1.7 \pm 0.2$ \\
\hline $\mathrm{CD}(n=20)$ & 1 & $10.1 \pm 12.1$ & $4.4 \pm 4.2$ & $2.5 \pm 1.9$ & $13.3 \pm 12.7$ & $1.7 \pm 0.3$ \\
\hline \multirow{2}{*}{$\mathrm{UC}(n=12)$} & 1 & $5.3 \pm 6.1$ & $6.8 \pm 5.7$ & $4.1 \pm 3.0$ & $11.5 \pm 10.6$ & $2.0 \pm 0.3$ \\
\hline & 2 & $18.1 \pm 16.7$ & $5.7 \pm 5.6$ & $1.6 \pm 1.4$ & $13.3 \pm 10.2$ & $1.6 \pm 0.4$ \\
\hline
\end{tabular}

Results are presented as mean \pm SD. Statistically significant differences between the frequencies of MNs and bridges in BNs from IBD patients before and after 1 mo of treatment and folate supplementation and subjects of control group are shown graphically and numerically in Figure 1 and for apoptotic and necrotic cells in Figure 2. 


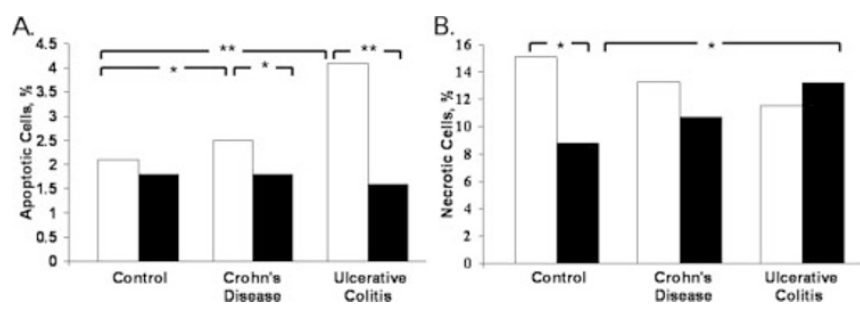

Figure 2. MN assay in lymphocyte cultures. Frequencies of apoptotic $(A)$ and necrotic $(B)$ cells in patients with IBD and controls before (open columns) and after (solid columns) $1 \mathrm{~m}$ of treatment that included folate supplementation for newly diagnosed patients and folate supplementation for control subjects. GEE models were used to assess significance of the differences with $* p<$ 0.05 .

tion or treatment and was similar for all three groups (1.7 in controls, 1.8 for CD patients, and 1.8 for UC patients, Table 3 ).

Cytogenetic damage in exfoliated epithelial cells. The frequency of MNs in buccal cells of the CD patients and controls slightly decreased after supplementation and treatment $(p=0.07$ and $p=0.11$, respectively, Table 4). However, in UC patients, a significant 3 -fold increase in the MN frequency was observed $(p=0.001)$. Furthermore, the frequency of MNs in buccal cells at the collection 2 was significantly higher in patients with UC than in controls $(p<0.002)$ and CD patients $(p<0.001$, Fig. 3). Similar changes in the MN frequencies were noted for degenerated cells in all three groups (Table 4). Specifically, second collections were characterized by a decrease in observed MNs for CD patients and controls and an increase for UC patients. The difference was also noticeable in the frequency of the degenerated cells that was not altered by treatment and supplementation in either group and was significantly higher in UC patients (18\% in CD patients and controls versus $26 \%$ in UC patients, $p=0.03$ ). No correlations were found between the frequency of MNs or the percentage of degenerated cells in exfoliated buccal cells and age, gender, or ethnicity.

MN assay was also conducted for urothelial cells (Table 5). However, data were less robust; many male subjects had relatively small numbers of cells available for scoring, resulting in zero $\mathrm{MN}$ frequencies in several categories. In controls, the $\mathrm{MN}$ frequency declined after folate supplementation (from 2.6 to $0.7 \mathrm{MNs} / 1000$ cells, $p=0.001$ ).

Comparison of lymphocytes and exfoliated epithelial cells. $\mathrm{MN}$ levels were almost 10 times higher in BNs (6.6-18.0 $\mathrm{MNs} / 1000$ cells) than in exfoliated buccal and urothelial cells

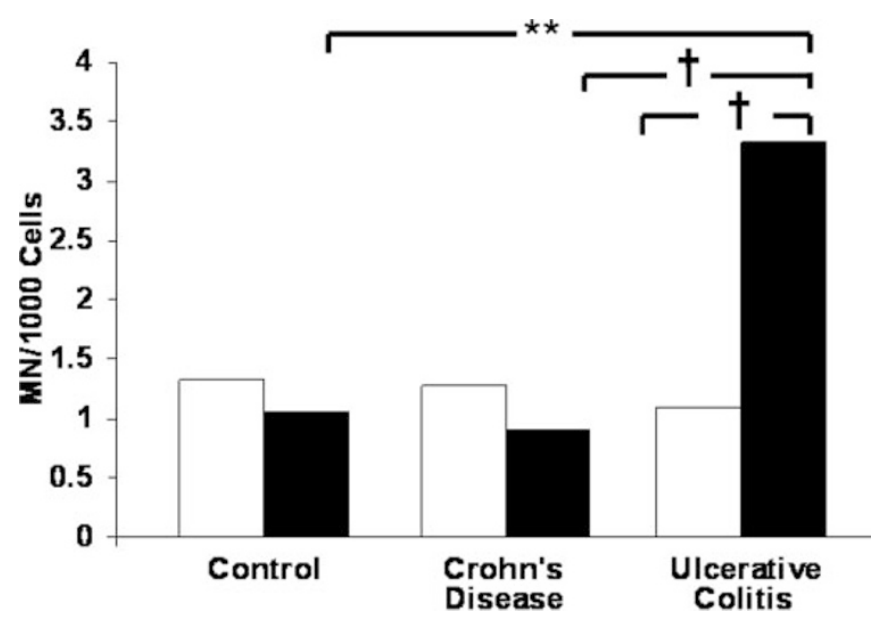

Figure 3. Frequency of MNs in exfoliated buccal cells in patients with IBD and controls before (open columns) and after (solid columns) 1 mo of folate supplementation (all subjects) and treatment for newly diagnosed patients. GEE models were used to assess significance of the differences with $* * p<$ 0.01 , and $\dagger p \leq 0.001$.

(0.7-3.3 MNs/1000 cells). No correlations between individual levels of MNs were observed in the three cell types.

\section{DISCUSSION}

Results of this longitudinal case-control study of pediatric IBD suggest that the two primary types of pediatric IBD (UC and $\mathrm{CD}$ ) each have distinctly different patterns of cytogenetic response after 1 mo of treatment that included folate supplementation. CD patients showed decreased frequencies of MNs and chromosome bridges in lymphocytes and MNs in exfoliated epithelial cells. However, patients with UC experienced a trend of increased MN frequencies in both lymphocytes and exfoliated buccal cells. Further, after treatment and folate supplementation, MN frequency was higher in patients with UC than in controls $(p<0.001)$ and patients with $\mathrm{CD}(p<$ 0.001 ), suggesting that the mechanism for cytogenetic damage may differ between pediatric UC and CD. These differences cannot be directly attributed to folate supplementation. However, folate supplementation appears to be beneficial to controls. Furthermore, the reduction of cytogenetic damage after folate supplementation in controls provides evidence of a protective effect against oxidative stress. Another possible mechanism of folate protection is prevention of MNs caused by excessive uracil incorporation or hypomethylation of DNA (28).

Table 4. Results of the MN assay for buccal cells

\begin{tabular}{|c|c|c|c|c|c|c|}
\hline Group & Collection & \multicolumn{2}{|c|}{ Normal cells } & \multicolumn{2}{|c|}{ Degenerated cells } & $\%$ \\
\hline Control $(n=26)$ & 1 & $1.3 \pm 1.2$ & 0.11 & $2.2 \pm 1.4$ & 0.17 & $19.1 \pm 7.4$ \\
\hline \multirow[t]{2}{*}{$\mathrm{CD}(n=24)$} & 1 & $1.3 \pm 1.0$ & 0.07 & $0.3 \pm 1.1$ & 0.87 & $17.4 \pm 5.6$ \\
\hline & 2 & $0.9 \pm 1.0$ & & 0 & & $20.1 \pm 6.1$ \\
\hline $\mathrm{UC}(n=17)$ & 1 & $1.1 \pm 0.8$ & 0.001 & $0.3 \pm 0.4$ & $<0.001$ & $26.7 \pm 8.1$ \\
\hline
\end{tabular}

All results are presented as mean \pm SD. $p$ Values reflect significant differences in MN frequency between the baseline (collection 1) and after 1 mo of folate supplementation and treatment (collection 2), using GEE analysis, which accounts for the repeated measurements on the same subject. 
Table 5. Results of the MN assay for urothelial cells

\begin{tabular}{|c|c|c|c|c|c|c|}
\hline Group & Collection & \multicolumn{2}{|c|}{ Normal cells } & \multicolumn{2}{|c|}{ Degenerated cells } & $\%$ \\
\hline Control $(n=16)$ & 1 & $2.6 \pm 1.9$ & 0.001 & $0.6 \pm 0.5$ & 0.05 & $27.0 \pm 12.1$ \\
\hline \multirow[t]{2}{*}{$\mathrm{CD}(n=12)$} & 1 & 0 & & $0.6 \pm 0.7$ & 0.38 & $44.4 \pm 28.2$ \\
\hline & 2 & $1.9 \pm 1.9$ & & $0.6 \pm 0.9$ & & $27.0 \pm 16.5$ \\
\hline $\mathrm{UC}(n=10)$ & 1 & $2.3 \pm 2.6$ & 0.89 & $1.4 \pm 1.7$ & & $28.7 \pm 16.7$ \\
\hline
\end{tabular}

All results are presented as mean SD. $p$ values reflect significant differences between cytogenetic parameters at the baseline (collection 1) and after 1 mo of folate supplementation and treatment (collection 2 ), by the GEE method, taking into account by-pair comparisons for each participant. Several subjects did not have sufficient numbers of exfoliated urothelial cells and were excluded from this analysis. $p$ values were not calculated if one of the two visits resulted in zero MN frequency.

$\mathrm{MN}$ frequency in BNs is a common measure used to assess the rate of DNA damage (21). Recently, interest in evaluation of cytogenetic damage in epithelial cells has increased, especially since exfoliated cells, including those of oral mucosa, are a common origin of human cancers (23). In our study, buccal cells were of special interest because increased cytogenetic damage in this target tissue suggests overall effects in the GI tract, particularly for CD patients. Baseline MN frequencies in both cells types of our subjects were similar to those reported in the literature: $5-25 \mathrm{MNs} / 1000$ cells in BNs and $0.5-5 \mathrm{MNs} / 1000$ cells in epithelial cells $(21,24)$.

Typical frequencies of IBD range from 12 to 40 per 100,000 (3). IBD was once considered a rarity in pediatric patients, but now $25 \%-30 \%$ of all new patients with CD and $20 \%$ of all new patients with UC are younger than 20 y old (29). The increase of IBD in pediatric patients and dearth of information on pathophysiologic mechanisms of pediatric IBD are the main reasons why this study focused primarily on children (10). In addition to the normal symptoms, children with IBD may experience prominent extraintestinal manifestations, such as growth failure and delayed puberty (29). Furthermore, the risk of colorectal cancer in patients with IBD is increased 4- to 20-fold when compared with the general population $(3,30)$.

Folate deficiency may also influence IBD status as studies have reported an association between the two (4). Folate, which occurs naturally in food, and folic acid, found in supplements and fortified foods in synthetic form, are watersoluble forms of the B vitamins. A recent review pointed out that the general population often has suboptimal levels of folate (28). Similarly, in the subset of our cohort, we found that folate levels in healthy control children were below average $(600 \mathrm{ng} / \mathrm{mL}$ versus $755 \mathrm{ng} / \mathrm{mL}$ in IBD patients, Table 2). Furthermore, after 1 mo of supplementation, control group levels significantly increased to $754 \mathrm{ng} / \mathrm{mL}$. While folate in IBD patients also increased, levels in collection 2 were not statistically different from those in collection 1 . Several factors may contribute to the lack of statistical significance in IBD patients including inadequate dose of folate supplementation, effects of current treatments, or changes in diet. For example, one of the main treatments for IBD, SASP, also increases the risk of folate deficiency (8).

Low levels of folate can also lead to increased cytogenetic damage (31). However, folate supplementation can normalize this damage in human lymphocytes and exfoliated buccal cells
(24). A large population study in Australia showed that plasma folate and $\mathrm{B}_{12}$ levels in young individuals were more important than vitamin $\mathrm{C}$ and $\mathrm{E}$ levels in minimizing chromosomal damage (28). An increased MN frequency and chromosomal damage in adult lymphocytes and erythrocytes of splenectomized individuals has been associated with low folate levels $(15,24)$. We observed similar results in our control groups, who also had relatively low folate levels. After supplementation, there was a statistically significant decrease in necrotic cells, a suggestive decrease in apoptotic cells and NBs in lymphocytes, and a slight decrease of $\mathrm{MN}$ in buccal cells. Similar trends were seen in CD patients but not UC patients.

Responses to supplementation and the levels of cytogenetic damage differed between UC and CD patients in both buccal cells and lymphocytes. Similar to the control group, CD patients showed a decrease in cytogenetic damage after 1 mo of treatment and folate supplementation. However, UC patients showed an opposite effect; they experienced a noticeable increase in cytogenetic damage in the same period. Thus, the mechanism for cytogenetic damage in UC may differ from that in $\mathrm{CD}$. Further, this difference may reflect variations in the timetable for inflammatory changes in $\mathrm{UC}$ versus $\mathrm{CD}$ or possibly effects of specific medications used for this type of pediatric IBD. However, a relatively small sample size precluded further analysis of specific drug effects. Even as there was no correlation of cytogenetic damage in individual subjects, the responses in all patient groups were similar in three cell types. For instance, UC patients experienced increases in genotoxicity after treatment in both buccal cells and lymphocytes, while CD patients showed decreases. Cytogenetic damage in lymphocytes and urothelial cells more likely reflect an overall general response of the body, while buccal cells were expected to reveal damage in the target site, the GI tract.

Although we cannot attribute the modification of cytogenetic damage in blood lymphocytes and exfoliated epithelial cells in IBD patients solely to folate, the month-long supplementation appeared beneficial to controls and possibly to $\mathrm{CD}$ patients. In contrast, the UC group experienced increased levels of cytogenetic damage. However, our study design did not allow for differentiation between the effect of the standard IBD regimen, including folate supplementation, and the effect of treatment or folate supplementation alone. Additional larger studies will be needed to verify that these preliminary findings of the cytogenetic difference in treated IBD patients are con- 
sistent in both adult and pediatric patients and to address dynamics of genotoxicity of different treatment and vitamin supplementation regimens. The effect of folate supplementation alone compared with anti-inflammatory therapies for the underlying IBD on cytogenetic injury should also be systematically investigated.

Acknowledgments. The authors thank R. Momi, and C. Tran for their help with the scoring and J. Cooper, J. Madden, and N. Sweeters for assistance with subject recruitment. Dr. M. Smith's support of this project is appreciated. This study would not be possible without the cooperation of our patients and control subjects.

\section{REFERENCES}

1. Shashidhar H, Integlia M, Grand R 1995 Clinical Manifestations of Pediatric Inflammatory Bowel Disease. In: Kirsner JB, Shorter RG (eds) Inflammatory Bowel Disease. Williams \& Wilkins, Baltimore, pp 326334

2. Bernstein CN, Blanchard JF, Kliewer E, Wajda A 2001 Cancer risk in patients with inflammatory bowel disease: a population-based study. Cancer 91:854-862

3. Lewis JD, Deren JJ, Lichtenstein GR 1999 Cancer risk in patients with inflammatory bowel disease. Gastroenterol Clin North Am 28:459-477

4. Mahmud N, Molloy A, McPartlin J, Corbally R, Whitehead AS, Scott JM, Weir DG 1999 Increased prevalence of methylenetetrahydrofolate reductase C677T variant in patients with inflammatory bowel disease, and its clinical implications. Gut 45:389394

5. Orii S, Sugai T, Nakano O, Yoshinari H, Sato S 1991 Acute promyelocytic leukemia in Crohn's disease. Case report and review of the literature. J Clin Gastroenterol 13:325-327

6. Han PD, Burke A, Baldassano RN, Rombeau JL, Lichtenstein GR 1999 Nutrition and inflammatory bowel disease. Gastroenterol Clin North Am 28:423-443

7. Lashner BA 1993 Red blood cell folate is associated with the development of dysplasia and cancer in ulcerative colitis. J Cancer Res Clin Oncol 119:549 554

8. Halsted CH, Gandhi G, Tamura T 1981 Sulfasalazine inhibits the absorption of folates in ulcerative colitis. N Engl J Med 305:1513-1517

9. Hanauer S, Meyers S, Sachar D 1995 The Pharmacology of Antiinflammatory Drugs in BD In: Kirsner JB, Shorter RG (eds) Inflammatory Bowel Disease. Williams \& Wilkins, Baltimore, pp 643-663.

10. Heyman MB, Kirschner BS, Gold BD, Ferry G, Baldassano R, Cohen SA, Winter HS, Fain P, King C, Smith T, El-Serag HB 2005 Children with early-onset inflammatory bowel disease (IBD): analysis of a pediatric IBD consortium registry. J Pediatr 146:35-40

11. Hyams J, Markowitz J, Otley A, Rosh J, Mack D, Bousvaros A, Kugathasan S, Pfefferkorn M, Tolia V, Evans J, Treem W, Wyllie R, Rothbaum R, del Rosario J, Katz A, Mezoff A, Oliva-Hemker M, Lerer T, Griffiths A 2005 Evaluation of the pediatric Crohn disease activity index: a prospective multicenter experience. J Pediatr Gastroenterol Nutr 41:416-421

12. Oliva-Hemker M, Fiocchi C 2002 Etiopathogenesis of inflammatory bowel disease: the importance of the pediatric perspective. Inflamm Bowel Dis 8:112-128

13. Kang MH, Genser D, Elmadfa I 1997 Increased sister chromatid exchanges in peripheral lymphocytes of patients with Crohn's disease. Mutat Res 381:141-148
14. Grisham MB 1994 Oxidants and free radicals in inflammatory bowel disease. Lancet 344:859-861

15. MacGregor JT, Wehr CM, Hiatt RA, Peters B, Tucker JD, Langlois RG, Jacob RA, Jensen RH, Yager JW, Shigenaga MK, Frei B, Eynon BP, Ames BN 1997 'Spontaneous' genetic damage in man: evaluation of interindividual variability, relationship among markers of damage, and influence of nutritional status. Mutat Res 377:125-135

16. Jahanshahi G, Motavasel V, Rezaie A, Hashtroudi AA, Daryani NE, Abdollahi M 2004 Alterations in antioxidant power and levels of epidermal growth factor and nitric oxide in saliva of patients with inflammatory bowel diseases. Dig Dis Sci 49:1752-1757

17. Rosin MP, Gilbert AM 1990 Modulation of genotoxic effects in humans. Prog Clin Biol Res 340E:351-359

18. Aghdassi E, Wendland BE, Steinhart AH, Wolman SL, Jeejeebhoy K, Allard JP 2003 Antioxidant vitamin supplementation in Crohn's disease decreases oxidative stress. a randomized controlled trial. Am J Gastroenterol 98:348-353

19. Barbosa DS, Cecchini R, El Kadri MZ, Rodriguez MA, Burini RC, Dichi I 2003 Decreased oxidative stress in patients with ulcerative colitis supplemented with fish oil omega-3 fatty acids. Nutrition 19:837-842

20. Fenech M, Holland N, Chang WP, Zeiger E, Bonassi S 1999 The HUman MicroNucleus Project An international collaborative study on the use of the micronucleus technique for measuring DNA damage in humans. Mutat Res 428:271-283

21. Neri M, Ugolini D, Bonassi S, Fucic A, Holland N, Knudsen LE, Sram RJ, Ceppi M, Bocchini V, Merlo DF 2006 Children's exposure to environmental pollutants and biomarkers of genetic damage. II. Results of a comprehensive literature search and meta-analysis. Mutat Res 612:14-39

22. Bonassi S, Znaor A, Ceppi M, Lando C, Chang WP, Holland N, Kirsch-Volders M, Zeiger E, Ban S, Barale R, Bigatti MP, Bolognesi C, Cebulska-Wasilewska A, Fabianova E, Fucic A, Hagmar L, Joksic G, Martelli A, Migliore L, Mirkova E, Scarfi MR, Zijno A, Norppa H, Fenech M 2006 An increased micronucleus frequency in peripheral blood lymphocytes predicts the risk of cancer in humans. Carcinogenesis [Epub ahead of print]

23. Majer BJ, Laky B, Knasmuller S, Kassie F 2001 Use of the micronucleus assay with exfoliated epithelial cells as a biomarker for monitoring individuals at elevated risk of genetic damage and in chemoprevention trials. Mutat Res 489:147-172

24. Titenko-Holland N, Jacob RA, Shang N, Balaraman A, Smith MT 1998 Micronuclei in lymphocytes and exfoliated buccal cells of postmenopausal women with dietary changes in folate. Mutat Res 417:101-114

25. Titenko-Holland N, Moore LE, Smith MT 1994 Measurement and characterization of micronuclei in exfoliated human cells by fluorescence in situ hybridization with a centromeric probe. Mutat Res 312:39-50

26. Fenech M, Chang WP, Kirsch-Volders M, Holland N, Bonassi S, Zeiger E 2003 HUMN project: detailed description of the scoring criteria for the cytokinesis-block micronucleus assay using isolated human lymphocyte cultures. Mutat Res 534:65-75

27. Liang KY, Zeger SL 1993 Regression analysis for correlated data. Annu Rev Public Health 14:43 68

28. Fenech M 2001 The role of folic acid and Vitamin B12 in genomic stability of human cells. Mutat Res 475:57 67

29. Baldassano RN, Piccoli DA 1999 Inflammatory bowel disease in pediatric and adolescent patients. Gastroenterol Clin North Am 28:445-458

30. Friedman S, Rubin PH, Bodian C, Goldstein E, Harpaz N, Present DH 2001 Screening and surveillance colonoscopy in chronic Crohn's colitis. Gastroenterology 120:820-826

31. Fenech M, Crott JW 2002 Micronuclei, nucleoplasmic bridges and nuclear buds induced in folic acid deficient human lymphocytes-evidence for breakage-fusionbridge cycles in the cytokinesis-block micronucleus assay. Mutat Res 504: $131-136$ 